\title{
EULAR recommendations for the management of rheumatoid arthritis with synthetic and biological disease-modifying antirheumatic drugs
}

\begin{abstract}
Josef S Smolen, ${ }^{1,2}$ Robert Landewé, ${ }^{3}$ Ferdinand C Breedveld, ${ }^{4}$ Maxime Dougados, ${ }^{5}$ Paul Emery, ${ }^{6}$ Cecile Gaujoux-Viala, ${ }^{5,7}$ Simone Gorter, ${ }^{3}$ Rachel Knevel, ${ }^{4}$ Jackie Nam, ${ }^{6}$ Monika Schoels, ${ }^{2}$ Daniel Aletaha, ${ }^{1}$ Maya Buch, ${ }^{6}$ Laure Gossec, ${ }^{5}$ Tom Huizinga, ${ }^{4}$ Johannes W J W Bijlsma, ${ }^{8}$ Gerd Burmester, ${ }^{9}$ Bernard Combe, ${ }^{10}$ Maurizio Cutolo, ${ }^{11}$ Cem Gabay, ${ }^{12}$ Juan Gomez-Reino, ${ }^{13}$ Marios Kouloumas, ${ }^{14}$ Tore K Kvien, ${ }^{15}$ Emilio Martin-Mola, ${ }^{16}$ lain McInnes, ${ }^{17}$ Karel Pavelka, ${ }^{18}$ Piet van Riel, ${ }^{19}$ Marieke Scholte, ${ }^{14}$ David L Scott, ${ }^{20}$ Tuulikki Sokka, ${ }^{21}$ Guido Valesini, ${ }^{22}$ Ronald van Vollenhoven, ${ }^{23}$ Kevin L Winthrop, ${ }^{24}$ John Wong, ${ }^{25}$ Angela Zink, ${ }^{26}$ Désirée van der Heijde ${ }^{4}$
\end{abstract}

For numbered affiliations see end of the article

\section{Correspondence to Professor Josef S Smolen, Division of Rheumatology, Department of Medicine 3, Medical University of Vienna, Waehringer Guertel 18-20, A-1090 Vienna, Austria; josef.smolen@wienkav.at or josef.smolen@meduniwien. ac.at}

Accepted 3 February 2010 JSS and RL are joint first authors.

\begin{abstract}
Treatment of rheumatoid arthritis (RA) may differ among rheumatologists and currently, clear and consensual international recommendations on RA treatment are not available. In this paper recommendations for the treatment of RA with synthetic and biological disease-modifying antirheumatic drugs (DMARDs) and glucocorticoids (GCs) that also account for strategic algorithms and deal with economic aspects, are described. The recommendations are based on evidence from five systematic literature reviews (SLRs) performed for synthetic DMARDs, biological DMARDs, GCs, treatment strategies and economic issues. The SLR-derived evidence was discussed and summarised as an expert opinion in the course of a Delphi-like process. Levels of evidence, strength of recommendations and levels of agreement were derived. Fifteen recommendations were developed covering an area from general aspects such as remission/low disease activity as treatment aim via the preference for methotrexate monotherapy with or without GCs vis-à-vis combination of synthetic DMARDs to the use of biological agents mainly in patients for whom synthetic DMARDs and tumour necrosis factor inhibitors had failed. Cost effectiveness of the treatments was additionally examined. These recommendations are intended to inform rheumatologists, patients and other stakeholders about a European consensus on the management of RA with DMARDs and GCs as well as strategies to reach optimal outcomes of RA, based on evidence and expert opinion.
\end{abstract}

\section{INTRODUCTION}

The management of rheumatoid arthritis (RA) rests on several principles. Drug treatment, which comprises disease-modifying antirheumatic drugs (DMARDs), but also non-steroidal anti-inflammatory drugs and glucocorticoids (GCs), as well as non-pharmacological measures, such as physical, occupational and psychological therapeutic approaches, together may lead to therapeutic success. However, the mainstay of RA treatment is the application of DMARDs. It is DMARD treatment, especially, which has undergone dramatic changes during the past decade, providing previously unforeseen therapeutic dimensions. New and highly effective DMARDs have continued to emerge until the most recent years-in particular, biological agents which target tumour necrosis factor, the interleukin 1 (IL-1) receptor, the IL-6 receptor, B lymphocytes and T-cell costimulation. ${ }^{1}$ In addition, a chemical DMARD, leflunomide, has become available and compounds which have been in use for many decades, such as methotrexate (MTX) and sulfasalazine (SSZ), as well as GCs, have been re-examined in order to achieve better efficacy. For example, the use of high dose MTX ${ }^{2}$ and the disease-modifying effects of GCs, especially when combined with traditional DMARDs, ${ }^{3-7}$ are now well established. Furthermore, treatment strategies have changed during this period, initially by calling for early referral and early institution of DMARD treatment on the basis of respective evidence of clinical efficacy, ${ }^{8-10}$ and later by showing that tight control using composite measures of disease activity and appropriate switching of drug treatment are highly efficacious approaches. ${ }^{11-14}$

While all these data of clinical and observational trials on drugs and strategies have been highly enlightening, patients and rheumatologists are currently overwhelmed by this information which does not always allow one to decide easily and conclusively which path to follow when initiating or changing therapeutic strategies in patients with RA. Indeed, some inconsistencies in therapeutic targets and strategies among rheumatologists have been recognised in a survey performed at a recent annual European Congress of Rheumatology. ${ }^{15}$ These inconsistencies may be partly based on differences in attitudes among doctors caring for patients with RA, settings (academic centres vs private practice), patient preferences and reimbursement policies. Information on the current state of evidence for the efficacy of different agents or therapeutic strategies may also not always be regarded as sufficiently complete or available.

Along these lines, the European League Against Rheumatism (EULAR) has recently formulated major objectives, which among other aspects 
specify that "by 2012, EULAR will have provided standards of care and foster access to optimal care of people with musculoskeletal conditions in Europe" ${ }^{16}$ Since disease modification constitutes the most important therapeutic intervention in RA, it was the objective of this EULAR Task Force to find a consensus on recommendations for the management of RA with synthetic and biological DMARDs.

\section{METHODS}

The task force aimed at aggregating available information on disease modification in RA into practical recommendations. The basis of the activities of the task force were the EULAR standardised operating procedures for the development of recommendations, ${ }^{17}$ which suggest the institution of an expert committee in charge of consensus finding on the basis of evidence provided by a systematic literature review (SLR) and expert opinion. The task of developing management recommendations for RA was regarded as large and therefore warranted division of the topic into five main areas: (a) synthetic DMARDs as monotherapy or in combination without GCs; (b) GCs alone and in combination with synthetic DMARD(s); (c) biological DMARDs; (d) treatment strategies; (e) economic issues. The last aspect was deemed important to understand the cost implications of treating RA by retrieving the existing evidence; the fourth area was intended to look at the best approaches to attain the therapeutic goals, define the term 'strategy' as a long-term plan of action to achieve that goal; and, most importantly, the first three areas were related to the evidence available for the efficacy, safety and monitoring of currently employed drugs.

The recommendations will reflect the balance of efficacy and safety and will not deal in detail with the toxicity of DMARDs. The most important pieces of information in this regard are provided in separate publications on the SLRs, ${ }^{18-22}$ which indeed are part and parcel of these recommendations, since they provide their bases. Thus, the recommendations shown here will primarily deal with agents whose toxicity appears to be manageable, assuming that users are either aware of the respective risks or will adhere to the information provided in the package inserts. Also, where toxicity appears to be a major concern, a general warning will be included in the respective recommendation.

The expert committee comprised 25 rheumatologists, two patients, one infectious disease specialist, one health economist and five fellows. The members of this task force came from 12 European countries and from the USA. The expert committee was divided into five subgroups; each consisted of five to seven members including one fellow and dealt with one of the above topics. At the first meeting, these subgroups prioritised the research questions, defined the appropriate search terms and reported to the full committee, which took the final decisions by consensus.

Subsequently, the fellows, with the help of their mentors, performed the respective SLR searching PubMed, Embase, Medline and the Cochrane library and also recent abstracts, up to the middle of 2009. The SLRs included meta-analyses, systematic reviews, randomised controlled trials (RCTs), non-RCTs and observational studies, including data from registries. The individual research questions, in particular on the efficacy and toxicity of the agents under investigation, were examined by looking at the population of adult patients with RA, the type of agent, the control used for comparison and the outcome. If possible, outcome was quantified using effect sizes, which are unitless and therefore allow for the analysis of efficacy irrespective of the measures evaluated in individual clinical trials; these data will be solely discussed in the reports on the SLRs. Categorisations of evidence and strength of recommendation were determined according to the standards of the Oxford Centre for Evidence Based Medicine. ${ }^{23}$

At the second task force meeting, the fellows presented the results of the SLR in an aggregated form to the subgroups. The members of the subgroups debated and evaluated the evidence presented and formulated preliminary sets of recommendations. These proposals were reported to the entire task force, which discussed the suggestions on the recommendations in detail, amended them as deemed appropriate in the course of the consensus finding and took the final decisions. An ultimate round of refinement of the wording was done via electronic communication, by which also an anonymous voting on the level of agreement was performed. In addition, respondents were asked to indicate which of the statements were in line with their current treatment practice and, if not, whether they would change that practice. The task force started its work in December 2008 and finalised it in June 2009.

\section{RESULTS}

\section{Overarching principles}

Before dealing with the actual treatment recommendations, the task force discussed several principles that were deemed important to be conveyed to those with RA or involved with the management of RA. These principles for the care of patients with RA are of such generic nature that they were felt to be 'overarching' (table 1). The task force decided unanimously on these three principles.

(A) Rheumatologists are the specialists who should primarily care for patients with $R A$. This statement stems from the evidence that patients with RA followed up by rheumatologists, in comparison with other doctors, are diagnosed earlier, receive DMARD treatment more frequently and have better outcomes in all major characteristics of RA, in particular joint damage and physical function. ${ }^{24-28}$ Rheumatologists check the disease activity of their patients with RA with appropriate instruments and are well aware of the indications, contraindications and adverse effects of DMARDs; this has become of particular importance with the advent of modern treatments and strategies. Therefore, patients with inflammatory arthritis, in general, and suspected RA, in particular, should be referred to rheumatologists as early as possible, since a delay in such a referral is one of the most daunting causes of tardy institution of effective treatment. ${ }^{929}$ However, the task force intentionally added the term 'primarily' to this statement, since the management of patients with RA should be shared with primary care doctors and other health professionals in a multidisciplinary approach. Also, in countries lacking sufficient numbers of rheumatologists, this task may have to be taken over by other doctors with experience in caring for patients with RA.

(B) Treatment of patients with RA should aim at the best care and must be based on a shared decision between the patient and the rheumatologist. Two themes govern the contents of this principle-first, the term 'best care', which the task force felt to be conveyed by the subsequent recommendations, and second, the phrase 'shared decision' with the patient, which refers to the need to discuss treatment aims, management plans and reasons for the recommended approaches with the patient. 
Table 1 Recommendations for the management of rheumatoid arthritis with non-biological and biological disease-modifying antirheumatic drugs.

\begin{tabular}{ll} 
Overarching principles \\
\hline A & $\begin{array}{l}\text { Rheumatologists are the specialists who should primarily } \\
\text { care for patients with RA }\end{array}$ \\
B & $\begin{array}{l}\text { Treatment of patients with RA should aim at the best care } \\
\text { and must be based on a shared decision between the } \\
\text { patient and the rheumatologist }\end{array}$ \\
C & $\begin{array}{l}\text { RA is expensive in regards to medical costs and productivity } \\
\text { costs, both of which should be considered by the treating } \\
\text { rheumatologist. }\end{array}$ \\
\hline
\end{tabular}

Final set of 15 recommendations for the management of RA

1 Treatment with synthetic DMARDs should be started as soon as the diagnosis of RA is made

2

Treatment should be aimed at reaching a target of remission or low disease activity as soon as possible in every patient; as long as the target has not been reached, treatment should be adjusted by frequent (every 1-3 months) and strict monitoring

3 MTX should be part of the first treatment strategy in patients with active RA When MTX contraindications (or intolerance) are present, the following DMARDs should be considered as part of the (first) treatment strategy: leflunomide, SSZ or injectable gold In DMARD naïve patients, irrespective of the addition of GCs, synthetic DMARD monotherapy rather than combination therapy of synthetic DMARDs may be applied

$6 \quad$ GCs added at low to moderately high doses to synthetic DMARD monotherapy (or combinations of synthetic DMARDs) provide benefit as initial short-term treatment but should be tapered as rapidly as clinically feasible If the treatment target is not achieved with the first DMARD strategy, addition of a biological DMARD should be considered when poor prognostic factors are present; in the absence of poor prognostic factors, switching to another synthetic DMARD strategy should be considered other synthetic DMARDs with or without GCs, biological DMARDs should be started*; current practice would be to start a TNF inhibitor (adalimumab, certolizumab, etanercept golimumab, infliximab) $†$ which should be combined with MTX*

9 Patients with RA for whom a first TNF inhibitor has failed should receive another TNF inhibitor, abatacept, rituximab or tocilizumab

In cases of refractory severe RA or contraindications to biological agents or the previously mentioned synthetic DMARDs, the following synthetic DMARDs might be also considered, as monotherapy or in combination with some of the above: azathioprine, ciclosporin A (or exceptionally, cyclophosphamide)

11 Intensive medication strategies should be considered in every patient, although patients with poor prognostic factors have more to gain

If a patient is in persistent remission, after having tapered GCs, one can consider tapering biological DMARDsł, especially if this treatment is combined with a synthetic DMARD

In cases of sustained long-term remission, cautious titration of synthetic DMARD dose could be considered, as a shared decision between patient and doctor DMARD naïve patients with poor prognostic markers might be considered for combination therapy of MTX plus a biological agent

When adjusting treatment, factors apart from disease activity such as progression of structural damage, comorbidities and safety concerns should be taken into account

Symbols * $\dagger$ and $\ddagger$ refer to levels of evidence provided in table 2 .

DMARD, disease-modifying antirheumatic drug; GCs, glucocorticoids; MTX

methotrexate; RA, rheumatoid arthritis; SSZ, sulfasalazine; TNF, tumour necrosis factor.
(C) $R A$ is expensive in regards to medical costs and productivity costs, both of which should be considered by the treating rheumatologist. The expert committee wished to encapsulate that the direct and indirect costs of RA, especially if insufficiently treated, are very high. ${ }^{28} 30-33$ Modern treatments, particularly biological agents, are expensive, ${ }^{30} 3435$ but may enable lowering of short- and long-term indirect costs of disease-an actuality that should be kept in mind for individual treatment approaches as well as reimbursement considerations. This underlying principle also reinforces the decision to evaluate economic aspects in relation to the individual recommendations to examine the cost effectiveness of RA treatment.

\section{Recommendations}

In each subgroup, the members discussed the evidence provided by the fellows in their SLRs in detail and agreed on five to eight recommendations for the respective topic. These preliminary statements on the management of RA with synthetic DMARDs, GCs and biological agents, as well as on treatment strategies and economic aspects, were subsequently reviewed intensively by the whole task force, synthesised and voted upon. This process led to 15 recommendations on drug management and treatment strategies. Each of these 15 recommendations was then subjected to an economic valuation in accordance with the results obtained by the economics subgroup of the task force.

The 15 recommendations (detailed in table 1) are presented in the text below in an abbreviated version. The levels of evidence and strengths of recommendation for each recommendation are then shown in table 2 and the economic valuation in table 3. The 15 recommendations are ordered by a logical sequence or procedural and chronological hierarchy rather than by any major weight of importance, with the exception of the first two points which constitute the foundation of all subsequent items. They also serve as basis for the algorithm provided in figure 1 .

(1) Synthetic DMARDs early-The task force was unanimous in its view that in the vast majority of patients with RA the first treatment approach should include synthetic DMARDs, since a significant proportion of patients can attain a state of very low disease activity or remission ${ }^{36-39}$; the types of DMARD with evidence of efficacy will be discussed in items 3-6. Moreover, since any delay in the start of DMARD treatment in patients with RA may lead to a worse outcome in comparison with an early start of treatment, 81040 DMARD treatment should be started as soon as a diagnosis of RA has been made. However, a diagnosis of RA in its earliest stage is not always easy and a suspected diagnosis of RA may be sufficient to initiate DMARD treatment. Importantly, American College of Rheumatology (ACR) and EULAR have collaboratively developed new criteria that are pertinent for this early phase of the disease. ${ }^{41}$

(2) Treatment targeting remission or low disease activityUndoubtedly, attaining a state of remission or low disease activity leads to better structural and functional outcomes than allowing residual disease activity ${ }^{11} 42-46$ and the earlier such a state is achieved the better. ${ }^{43} 47$ Thus, remission is the primary therapeutic aim, especially in early RA, though low disease activity may be an appropriate alternative, especially in patients with longstanding RA, as was also concluded by an expert committee recently engaged in defining a treatment target for RA. ${ }^{48}$ Strategic trials have shown that aiming at 
Table 2 Level of evidence, grade of recommendation and level of agreement

\begin{tabular}{llll}
\hline Recommendation & Level of evidence & $\begin{array}{l}\text { Grade of } \\
\text { recommendation }\end{array}$ & Level of agreement \\
\hline 1 & 1a & A & $9.9 \pm 0.4$ \\
2 & 1b & A & $9.7 \pm 0.7$ \\
3 & 1a & A & $9.8 \pm 0.5$ \\
4 & 1a & A & $8.6 \pm 1.5$ \\
5 & 1a- & A & $8.5 \pm 2.0$ \\
6 & 1a- & A & $8.7 \pm 1.7$ \\
7 & 5 & D & $8.8 \pm 1.7$ \\
8 & *b & *A & $9.3 \pm 1.5$ \\
& †4 & † & \\
9 & 1b & A & $9.5 \pm 0.9$ \\
10 & 1a- & B & $8.1 \pm 1.6$ \\
11 & 1b & B & $9.2 \pm 1.2$ \\
12 & 3b & B & $8.4 \pm 1.6$ \\
13 & 4 & C & $8.5 \pm 1.9$ \\
14 & 2b & C & $8.0 \pm 2.3$ \\
15 & 3b & C & $9.5 \pm 1.1$ \\
\hline
\end{tabular}

Symbols refer to the corresponding symbols in the recommendations presented in table 1 and show the respective evidence for those.

low disease activity or remission by adjusting treatment every 1-3 months in conjunction with strict monitoring is associated with a better clinical, radiographic and functional outcome than with an unstructured followup. ${ }^{11} 1349$ Thus, the treatment target should preferably be reached, or almost reached, within 3 months and definitely attained by a maximum of 6 months; while this time frame was not directly tested in comparative trials, this expert opinion is based on the use of a 1-3 months' period for switching treatments in strategy trials ${ }^{11-14}$ and on data showing that disease activity states at 3-6 months after treatment initiation predict outcome at later time points. ${ }^{50}$ Within this time frame of 3-6 months patients should be followed up meticulously (every month if necessary) and existing treatment should be intensified or ultimately changed for another. ${ }^{48}$ In line with these recommendations, monitoring should be regularly performed. While several different measures have been employed in various strategy trials, ${ }^{21}$ expert opinion has recently suggested using composite measures of disease activity which include joint counts. ${ }^{48}$ Valid measures for this purpose have been recently reviewed and include the Disease Activity Score (DAS), 28-joint count DAS (DAS28), Simplified Disease Activity Index and Clinical Disease Activity Index. ${ }^{51}$

(3) MTX as initial choice-MTX is a highly effective drug for disease modification in RA, 52 and more recent insights suggest that MTX at higher weekly doses (20-30 mg) is more effective than MTX at lower weekly doses (7.5-15 mg). ${ }^{253}$ MTX is considered the anchor drug in RA, ${ }^{54}$ both on the basis of its efficacy as monotherapy and on the basis of its ability to increase the efficacy of biological DMARDs when used in combination, ${ }^{55-59}$ as well as the beneficial long-term safety profile. ${ }^{60} \mathrm{MTX}$ is effective in DMARD naive patients with early RA, 1349 5661 and its clinical efficacy has neither been surpassed by other synthetic DMARDs nor consistently by tumour necrosis factor (TNF) inhibitor monotherapy. ${ }^{37555662}$ For these reasons the task force considered that MTX should be instituted at the earliest time point in patients with
RA. This statement comprises three items in addition to the recommendation for using MTX: first, it uses the wording 'part of the first treatment strategy', implying that MTX may have to be combined with other agents (see below); second, it refers to 'active RA', implying that patients with low disease activity may not necessarily need treatment with MTX; and third, the statement indicates implicitly that a strategy using MTX should be applied also to patients with active RA who have previously not received MTX, but only other synthetic DMARDs. Obviously this recommendation does not pertain to patients for whom a contraindication for MTX use is present (see below).

(4) Leflunomide, SSZ or injectable gold-There is currently insufficient evidence that leflunomide, SSZ or intramuscular gold salts are inferior to MTX. ${ }^{37} 38$ 62-64 Nevertheless, because of the wealth of efficacy and safety data available for MTX, the three mentioned DMARDs should be used instead of MTX as first DMARD treatments mainly if there are contraindications to (or intolerance of) MTX. In analogy with the previous paragraph, these MTX alternatives should also be considered as a part of a treatment strategy. The rather prominent place of parenteral gold salts has been the subject of intensive debate, but can be justified by the currently available high-level evidence, ${ }^{63} 6566$ and this decision was ultimately backed by the majority of the task force. In addition to the drugs mentioned above, antimalarial drugs (hydroxychloroquine and chloroquine) are also used in RA. They show some efficacy as monotherapy with respect to signs and symptoms ${ }^{67}$ and are frequently used as part of combination therapies. ${ }^{42} 6869$ It is, however, not clearly established if antimalarial drugs confer additional efficacy in combination therapy. In addition, antimalarial drugs do not inhibit structural damage sufficiently, especially in comparison with other agents such as SSZ. ${ }^{70}$ Therefore they have not been mentioned more prominently in the recommendation statement. Nevertheless, on the basis of their clinical efficacy as monotherapy they may have some value in patients with very mild disease who have contraindications to other compounds.

(5) Synthetic DMARD monotherapy or combination therapyOver the past two decades, combination therapy with various synthetic DMARDs has been suggested to convey superior efficacy in comparison with monotherapy. ${ }^{72} 686971$ Results of clinical trials testing the addition of synthetic DMARDs to MTX in patients with residual disease activity despite MTX treatment have often been used to support the assumption of an added benefit ${ }^{7273}$; however, in these studies an appropriate control (switch) arm was lacking and the proportion of responders receiving combination therapy did not exceed the proportion of responders receiving the monotherapy components. ${ }^{74}$ An important fact to consider to truly appreciate the content of this recommendation, however, is that in most clinical trials comparing combination therapy with monotherapy head to head, GCs were either mandatory in the combination therapy arm or GC use was different between both arms, which probably explains the superiority of combination therapy. ${ }^{74}$ Several other trials suggest that in the absence of GCs neither a start with combinations of synthetic DMARDs nor a step up 
combination therapy are better than monotherapies or switching DMARDs for the major outcomes. ${ }^{49} 75-77$ The SLR on this allowed a firm conclusion to be drawn. ${ }^{18}$ Furthermore, in DMARD naïve patients the balance of efficacy and toxicity favours MTX monotherapy versus combination therapy, while the evidence is inconclusive in DMARD inadequate responders. ${ }^{78}$ Therefore, the task force decided to use the word 'may' here. It is important to keep in mind that if combination therapy with synthetic DMARDs does not allow the treatment target to be achieved, it is impossible to disentangle which of the agents was insufficiently effective, precluding better usage of synthetic DMARDs. The statement contains yet another element-namely, the segment "irrespective of the addition of GCs". The committee was unanimous in its opinion that the addition of GCs to either monotherapy or combination therapy with DMARDs improves outcomes. However, studies allowing a direct comparison of GCs plus DMARD monotherapy versus GCs plus combination DMARDs have not been done.

(6) Glucocorticoids-GCs have been shown to have not only anti-inflammatory but clearly also disease-modifying properties. ${ }^{57980}$ The evidence that DMARD monotherapy is as efficacious as DMARD combination therapy suggests that the significantly better outcomes of trials using combinations of synthetic DMARDs plus GCs versus DMARD monotherapy might be due to the GC component. ${ }^{712} 42$ This notion finds important support in studies which show that adding GCs to DMARD monotherapy ${ }^{34}$ is beneficial. GC treatment has been added to DMARDs successfully at low doses ( $<10 \mathrm{mg}$ / day), ${ }^{34} 42$ but more rapid improvement may be achieved by addition of GCs at higher doses for the short term. ${ }^{7}$ ${ }^{49}$ However, the added efficacy of high-dose GCs has not yet been compared with that of low-dose GCs and, therefore, sufficient evidence for this is lacking. Importantly, long-term use of GCs can lead to adverse events, ${ }^{81}$ but there may also be safety concerns in the intermediate term, although most studies on the toxicity of GCs are of low quality and short duration. Nevertheless, their toxicity, particularly in the intermediate to long term, should in the opinion of the task force not be disregarded and thus GCs should be used with caution and preferably for only short periods of time. Consequently, GCs should be tapered as rapidly as possible in accordance with the clinical situation. The safety of GCs was also an important aspect of the EULAR recommendations on the management of GC treatment. ${ }^{82}$

(7) Addition of a biological DMARD or switch to another synthetic $D M A R D$ - This statement introduces the importance of prognostic markers in treatment decisions in RA. Factors believed to predict bad outcome independently are (a) the presence of autoantibodies, that is, rheumatoid factor and/or anticitrullinated peptide antibodies, particularly at high levels; (b) high disease activity as measured by composite indices (DAS, DAS28, Simplified Disease Activity Index and Clinical Disease Activity Index), swollen joint counts or acute phase reactants ( $\mathrm{C}$ reactive protein, erythrocyte sedimentation rate); (c) early occurrence of erosions ${ }^{83-87}$; these factors have recently also been amalgamated into a risk model. ${ }^{88}$ The task force agreed that patients failing to reach the treatment target on an initial strategy with synthetic DMARDs, in whom poor prognostic markers as defined above are absent, could be switched to another synthetic DMARD strategy for 3-6 months before further decisions on the institution of a biological agent are taken; these other DMARDs have been mentioned in recommendation 4. However, patients for whom an initial DMARD failed and who have poor prognostic markers should have the opportunity to receive a biological DMARD in addition to their synthetic DMARD. Interestingly, closing a gap of information by using a control arm receiving active treatment, a recent study which was not part of the SLR reported that for patients with early RA who had failed to reach low disease activity after 3 months' MTX monotherapy, the addition of a TNF inhibitor yielded significantly better clinical outcomes than the addition of SSZ plus hydroxychloroquine. ${ }^{89}$ These data also corroborate the conclusions discussed in recommendations 5 and 6-namely, that a combination of synthetic DMARDs in the absence of added GCs (even triple treatment of MTX, SSZ and hydroxychloroquine) has limited efficacy and may not have higher efficacy than if the patients had been switched to SSZ, as was shown in the BeSt trial. ${ }^{12}$ This limited (but partly exhibited) efficacy of such a synthetic DMARD regimen also supports the expert opinion of switching patients for whom a first DMARD strategy has failed and who do not have bad prognostic markers to another DMARD (or eventually DMARD combination). In contrast, for patients for whom initial MTX or other synthetic DMARDs (ideally with GCs) has failed and who have bad prognostic indicators a biological DMARD, in general, and a TNF inhibitor, in particular, should be employed. Importantly, however, no randomised controlled or observational clinical trials to date have tested this approach of differential treatment based on prognostic factors. Therefore, this statement is at the level of an expert opinion, but is supported by various indirect evidence provided in the existing literature.

(8) Initiation of a TNF inhibitor-This expansion of statement No 7, which applies to patients followed according to that previous statement, emphasises that biological agents are effective if synthetic DMARDs have failed (level 1a, grade A) and that they should be combined with MTX (or other DMARDs), since this combination has greater efficacy than monotherapy with most biological agents; this is well established for TNF inhibitors on the basis of respective comparative phase III trials ${ }^{55}$ 56 and for rituximab and tocilizumab on the basis of comparative phase II trials ${ }^{58} 59$ (level $1 \mathrm{~b}$, grade A). At the time of the SLR, the only biological agents licensed in Europe for treating patients with RA with active disease despite synthetic DMARD treatment were the TNF inhibitors and tocilizumab; rituximab and abatacept are currently licensed only for use after failure of TNF inhibitors. In the USA, though not currently in Europe, abatacept can also be used in these former patients; in light of more recent clinical trial data, ${ }^{90} 91$ abatacept and rituximab may receive similar approval as first biological agents by the European regulatory authorities in due course. It is noteworthy that some TNF inhibitors such as adalimumab and etanercept are licensed as monotherapy on the basis of their efficacy in clinical trials, but the data on their clinical superiority compared with MTX monotherapy are partly mixed. ${ }^{55692}$ Recent data suggest that monotherapy with tocilizumab is more effective than monotherapy with DMARDs such as 
MTX $^{9394}$; however, this RCT did not include a third arm using the combination of both so that it is not clear to date whether in patients with early RA monotherapy with tocilizumab is similarly or less effective than combination therapy with tocilizumab and MTX. Currently, the largest array of safety information is available for the TNF inhibitors owing to their use for more than one decade and the availability of large long-term registries. These compounds comprise adalimumab, etanercept and infliximab, but certolizumab and golimumab have meanwhile also been approved. However, it should be borne in mind that this represents current expert opinion and may change over time, specifically with the recent approval of other biological agents as potential first biological agent for DMARD inadequate responders-namely, tocilizumab in Europe and abatacept in the USA and other non-European countries. It should also be mentioned here that anakinra, the IL-1 receptor antagonist, while effective in individual patients with RA, did not show a high level of clinical efficacy in clinical trials ${ }^{9596}$ and therefore has not been recommended as a major biological agent for use in RA.

(9) Abatacept, rituximab or tocilizumab-There is high-level evidence from one RCT each that abatacept, golimumab, rituximab and tocilizumab are effective in patients for whom TNF inhibitor therapy has failed ${ }^{97-100}$ (level 1b, grade A). These data are partly supported by observational studies stemming from registries which suggest that switching from one TNF inhibitor to another, as well as switching from TNF-blocking agents to rituximab, is beneficial. ${ }^{101-103}$ To date, the committee could not identify RCTs in which switching was appropriately compared between different biological agents and therefore a preference for a particular biological agent in this situation could not be established. ${ }^{104}$

(10) Azathioprine, ciclosporin A or cyclophosphamide-RA can run a course that is refractory to several DMARDs and biological agents and can be severely destructive and disabling. ${ }^{99} 100105106$ While in the previous recommendations four synthetic DMARDs and nine biological agents have been mentioned, allowing a variety of therapeutic options, refractoriness may and still will occur. In order to meet the needs of this group of patients, the task force has referred to agents for which the literature provides evidence on efficacy. However, one needs to bear the toxicity in mind, especially in the case of ciclosporin A and cyclophosphamide; the latter drug should only be used in exceptional situations. A number of presumed DMARDs were excluded here, because the evidence for their efficacy was deemed insufficient; these include D-penicillamine, minocycline, auranofin, tacrolimus and chlorambucil. With respect to antimalarial drugs we refer to the paragraph on recommendation 4.

(11) Intensive medication strategies - This statement supplements several of the previous recommendations on drug treatment. Advocating intensive medication strategies refers to content of the strategy, such as MTX plus GCs or MTX plus biological agents, as well as tight monitoring and rapid switching of treatments if treatment goals are not attained (benchmarking). ${ }^{12} 107$ The statement that patients with poor prognostic factors have more to gain finds its basis in the appreciation that patients with a favourable prognosis very often respond similarly to low-intensity monotherapy or intensive medication strategies, ${ }^{87} 88$ but that patients with a severe and aggressive disease course often do not respond sufficiently well to DMARD monotherapy or combination therapy without addition of GCs or biological agents.

(12) Tapering biological DMARDs-It is currently unclear how to continue or discontinue treatment in patients who have achieved remission. A thoroughly performed RCT on stopping synthetic DMARDs in patients in remission has shown that only about one-third of the patients who maintained their DMARDs flared as opposed to about two-thirds of those who stopped them ${ }^{108}$; moreover, remission was much harder to re-achieve after stopping DMARDs. ${ }^{109}$ This was also concluded in a recent metaanalysis devoted to this issue. ${ }^{110}$ The first aspect embedded in this statement relates to the duration of remission: it should be persistent - that is, having lasted for several months, before tapering of synthetic and/or biological DMARDs should be considered. However, before tapering DMARDs, GCs must have been tapered in line with statement No 6 and remission have persisted. The task force felt (by expert opinion) that biological agents could then be slowly tapered by expanding the interval between doses or reducing the dose, while synthetic DMARDs should be continued. No particular time frame was given here, since there are no data available; from an expert opinion's view remission for at least 12 months might be regarded as 'persistent'. 110

(13) Tapering of synthetic DMARDs-This statement follows the preceding one, suggesting that tapering synthetic DMARD treatment in cases of longstanding remission could be considered after GCs and biological agents have been discontinued. Evidence supporting such an approach does not exist-neither details of a time frame nor dosing or interval duration during the tapering process. Thus, the means of tapering is left to the discretion of patient and doctor. However, in light of the available data showing that stopping DMARDs is associated with an increased flare frequency, 108110 the committee felt that tapering should be performed cautiously and assessed rigorously.

(14) Biological treatment in DMARD naïve patients While biological DMARDs, in line with statements Nos 7 and 8, should, in general, be applied to patients for whom synthetic DMARD(s) have failed, the committee strongly felt that there are some patients for whom first-line biological treatment combined with MTX has to be considered. Such patients will usually have unfavourable prognostic signs, including very active disease or early structural damage. Currently, only TNF inhibitors are licensed for such patients, but other biological agents may receive similar approval with more trial data in the future. When evaluating results of trials using TNF inhibitors plus MTX in MTX naïve individuals and studies of the same compounds in patients with active disease despite MTX treatment, 1555661 111-113 patients naive to MTX had higher response rates than MTX insufficient responders, but many of the MTXnaive patients in the combination therapy arms would have responded to MTX monotherapy anyway. Thus, while, there is also additional evidence from strategic trials that employing TNF inhibitors plus MTX early is an effective treatment, ${ }^{3649}$ more recent data suggest 


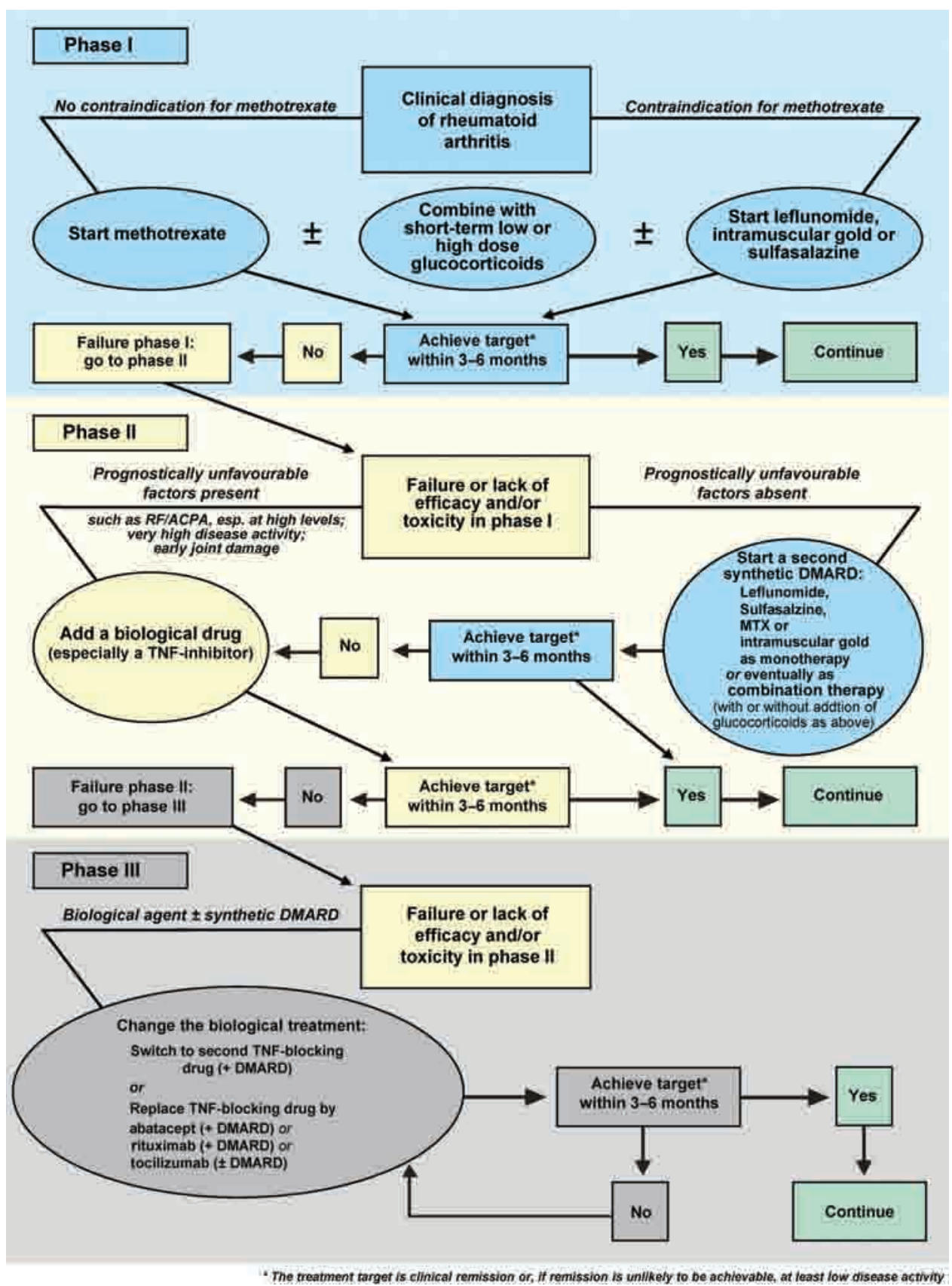

Figure 1 Algorithm based on the European League Against Rheumatism recommendations on rheumatoid arthritis management. DMARD, diseasemodifying antirheumatic drug; MTX, methotrexate; RF/ACPA, rheumatoid factor/anti-citrullinated peptide antibodies; TNF, tumour necrosis factor. ${ }^{*}$ The treatment target is clinical remission or, if remission is unlikely to be achievable, at least low disease activity.

that this approach may not be more effective in patients with early RA than starting synthetic DMARDs first and adding a biological agent to the DMARD rapidly (in that study after 3 months) if active disease prevails. ${ }^{114}$ However, hitherto no clinical trial has examined the actual expert-based recommendations to use such a strategy in few, selected patients as described above. Indeed, this statement received the lowest level of agreement (8.0/10) and it was the only item for which a large number of rheumatologists stated that it was not their current practice and that this recommendation would change their practice.

(15) Adjustment of treatment-Prudence and knowledge will guide one to bear toxicity of agents and comorbidities in mind when prescribing drugs for RA. However, the rapidity of progression of joint damage, in addition to disease activity and other prognostic factors, may support decision-making in relation to statements Nos 7 and 14, especially if joint damage appears to progress considerably despite the achievement of the desired treatment target; however, lag periods ${ }^{47}$ have to be taken into consideration before making such decision.

\section{Economic aspects}

The cost effectiveness of the therapeutic measures recommended above has been assessed in detail by a dedicated SLR, which is also published separately. ${ }^{22}$ In sum, the available data suggest that all recommendations are known to be 
Table 3 Economic valuation of recommendations

\begin{tabular}{ll}
\hline Recommendation & $\begin{array}{l}\text { Level of evidence and strength of } \\
\text { recommendation for cost effectiveness }\end{array}$ \\
\hline 1 & NA \\
2 & $2 c, B$ \\
3 & $2 b, B$ \\
4 & $1 b, 2 b ; B$ \\
5 & $2 c, B$ \\
6 & $2 c, B ; 5, D$ \\
7 & $2 b, B$ \\
8 & $2 b, B$ \\
9 & $2 b, B$ \\
10 & $N A$ \\
11 & $N A$ \\
12 & $2 c, B$ \\
13 & $2 c, B$ \\
14 & $1 b, A$ (for being not cost effective ${ }^{*}$ ) \\
15 & NA \\
\hline
\end{tabular}

* Not cost effective on the group level assessed in the respective studies, but not necessarily on the level of the exceptional individual patient as suggested in the recommendation.

NA, not applicable.

Table 4 Research agenda

\begin{tabular}{ll}
\hline & Research agenda \\
\hline 1 & What is the efficacy of GCs when added to DMARDs other than MTX \\
& or combinations of synthetic DMARDs with MTX, such as GC plus \\
SSZ, compared with GC plus MTX and biological agents + MTX? \\
How comparable or different is the efficacy of the various biological \\
agents in patients with active disease despite MTX? \\
How comparable or different is the efficacy of the various biological \\
agents in patients who did not respond or lost response to TNF \\
inhibitors? \\
Can biological agents be stopped in sustained remission with \\
maintenance of remission, and how does stopping biological agents \\
compare with stopping GC plus MTX or stopping GC? \\
What is the best way to taper treatment with synthetic and \\
biological DMARDs in patients with longstanding remission? \\
(comparison of different tapering ways) \\
Which differences will exist when comparing treatment strategies \\
starting in parallel with MTX monotherapy plus GC, combination of \\
synthetic DMARDs including MTX plus GC, combination of synthetic \\
DMARDs including MTX without GC and biological agents plus MTX? \\
How big is the difference of clinical, functional, radiographic efficacy \\
when a treatment strategy aiming at remission by newly defined \\
ACR/EULAR remission criteria is compared with a strategy aiming at \\
achievement of low disease activity? \\
Can we find predictors of response to synthetic DMARDs and \\
different biological agents? \\
What is the effect of adding antimalarial drugs to MTX or to \\
MTX+SSZ? \\
How cost effective is treating individuals with exceptionally high risk of \\
rapid progression with biological agents versus synthetic DMARDs plus \\
GCs when compared with using a sequence of agents as mandated by \\
social security agencies or NICE? \\
5
\end{tabular}

This research agenda is partly based on recommendations derived by expert opinion for which sufficient evidence is lacking.

ACR/EULAR, American College of Rheumatology/European League Against

Rheumatism; DMARD, disease-modifying antirheumatic drug; GCs, glucocorticoids:

MTX, methotrexate; NICE, National Institute of Health and Clinical Excellence; SSZ

sulfasalazine; TNF, tumour necrosis factor.

cost effective with the exception of statement No 14 (table 3). However, an economic analysis considering only the exceptional patients considered in recommendation No 14 has not been performed. The committee does not preclude the possibility that in this particular category of patients, the approach of starting biological agents as first-line DMARD treatment may be cost effective.

\section{Research agenda}

Research questions have been formulated in all subgroups. These questions were assessed by the task force and the result of this discussion is summarised in table 4 .

\section{DISCUSSION}

The task force has formulated 15 brief statements on the management of RA with synthetic and biological DMARDs. These statements were mostly based on a SLR with consensus finding on the wording of the recommendations, but partly also solely based on expert opinion. By this process and by stating the respective level of evidence and strength of recommendation for each item, the committee adhered to the EULAR standardised operating procedures for the development of recommendations. ${ }^{17}$ Moreover, where evidence was lacking and the task force had to arrive at an expert opinion, a research agenda was formulated to expedite the generation of evidence in the future.

The reasoning behind each statement and, particularly, behind the recommendations' specific wordings is explained in detail in the results section and will not be repeated here. Importantly, the overall agreement with these statements, assessed anonymously several weeks after their formulation, was very high with means of $\geq 8 / 10$ for all and $>9 / 10$ for seven of the 15 items (statements Nos 1-3, 8, 9, 11 and 15). The lowest agreement $(8 / 10)$ was received by the recommendation to start biological agents plus MTX as first DMARD strategy in selected patients with very high disease activity and poor prognostic markers (No 14). Indeed, it was also the only item where many rheumatologists stated that it was not their current practice and that this recommendation would change their current treatment practice (data not shown).

Dividing the task into five specific areas may have helped unambiguous conclusions to be reached. Three of these areas were related to actual pharmacological treatment. Moreover, separating the SLRs on synthetic DMARDs into those with and those without addition of GCs facilitated the derivation of recommendations on combination therapy with a clarity that had previously been unappreciated; at the same time, this clarity raised new questions which require further elucidation.

It is worth noting that the task force felt that the best evidence for efficacy was available for four synthetic DMARDs (MTX, leflunomide, SSZ and parenteral gold; statements Nos 3 and 4) and eight biological agents (adalimumab, certolizumab, etanercept, golimumab, infliximab, abatacept, rituximab and tocilizumab; statements Nos 7-9). These 12 agents are also clearly stated in the itemised recommendation sentences. Two additional agents are mentioned in the text only-namely, antimalarial drugs and anakinra, because while effective in RA, their efficacy is lower than that of other agents in their general class, synthetic or biological. A final group of DMARDs is referred to as a last resort for patients for whom the above drugs have failed (statement No 10). It should be mentioned here that GCs also have disease-modifying ability, ${ }^{80}$ but the task force does not suggest using them as monotherapy owing to their adverse event profile. ${ }^{81}$ Also, the readers are referred to the accompanying papers on the SLRs for full information on the efficacy of the respective agents.

The task force was convinced that modern treatment of RA should be goal oriented and governed by a strategic treatment approach. Remission or at the least low disease activity should be the therapeutic goal, in line with a recent recommendation on treatment goals in RA.48 115 On the way to attaining this target, patients should be closely monitored using composite disease 
activity measures ${ }^{116} 117$ and treatment adapted in accordance with the current recommendation if the treatment aim is not reached within preferably 3 , but at most, 6 months.

The task force also felt strongly that, in general, DMARD treatment should be started with MTX at appropriately high doses, possibly with the addition of GCs for the short term, before other measures are taken if the therapeutic goal is not reached within a maximum of 6 months. The type of other measures should depend on prognostic factors: while biological agents may be considered in all patients after lack of achievement of remission or low disease activity on the above treatment, such treatment is of more importance in the presence of poor prognostic factors, like the presence of autoantibodies, a high disease activity state or early erosive disease; it was felt quite appropriate to consider alternative synthetic DMARDs in the absence of poor prognostic factors. However, the task force also voiced its opinion that occasional patients with a particular need for rapid, highly effective intervention, may benefit from starting a biological agent plus MTX as a viable and useful option.

Particular emphasis emerged upon analyses of combination therapies with synthetic DMARDs. The SLR did not reveal general superiority of such combinations in comparison with respective monotherapies. Only in studies where GCs were added to synthetic DMARD(s) (or were given in higher doses or more frequently than in controls) was there compelling evidence for superiority of such combinations, but notably, the superiority was present regardless of whether GCs were added to synthetic DMARD monotherapy (such as MTX) or to combinations of synthetic DMARDs (such as triple treatment with MTX, SSZ and antimalarial drugs).

GCs have a special place in the discussion (statements Nos 5 , 6,8 and12). On the one hand, with respect to all outcomes, their efficacy as monotherapy, but especially in combination with synthetic DMARDs is indisputable. On the other hand, their toxicity, particularly in the intermediate to long term, was considered to be significant, ${ }^{82}$ so they should be used with caution and for only short periods of time. Tapering of GCs, but also of biological agents and eventually synthetic DMARDs, was an area of discussion too (statement No 13), but there is currently insufficient evidence available about outcomes and potential risks and hence how to proceed in this regards. Therefore, the committee felt that tapering should only occur in cases of sustained remission and should be part of the research agenda.

Figure 1 summarises the recommendations and the resulting algorithm. Phase I comprises the initiation of DMARD treatment once RA has been diagnosed (statements Nos 1-6). Phase II deals with patients who did not achieve the treatment target with strategy I (statements Nos 7 and 8); here, patients are stratified according to prognostic factors and this strategy contains the all steps until the use of the first biological agent. Phase III relates to patients for whom the first biological compound failed (statement No 9).

The recommendations on the management of RA provided here by the EULAR Task Force are not the first of their kind. Indeed, EULAR has already published recommendations for early RA, ${ }^{115}$ but the present document relates to all patients with RA, rather than only those with early RA or undifferentiated arthritis and provides far more detail about pharmacological compounds. However, in line with the guidance document by Combe et al, the first bullet point calls for a DMARD to be initiated as soon as RA is diagnosed.

Aside from the EULAR document on early RA management, the ACR has provided therapeutic recommendations for several years. ${ }^{118}$ However, its most recent 2008 recommendations are complex and may not fully cover several aspects of drug treatments and therapeutic strategies and goals. ${ }^{119}$ A comprehensive document published by the National Institute of Health and Clinical Excellence (NICE) of the $\mathrm{UK}^{29}$ at a time when our investigations were well advanced arrived at many conclusions that are supported by ours and vice versa, although the NICE publication does not consider biological treatments. Finally, many national rheumatological societies, such as the French or German societies, have published national guidance documents.

These EULAR recommendations have been developed by task force members from 12 European countries and the USA. They are meant to serve rheumatologists in Europe and elsewhere, although we are aware that not all agents mentioned here are approved everywhere and, indeed, some agents had not yet been approved in Europe when we dealt with the respective literature, in the expectation that they would be licensed by the time this manuscript was submitted for publication.

Beyond rheumatologists, the document is also provided for patients with RA to inform them about current treatment goals, strategies and opportunities, as recognised through the important participation of patients in the task force. Finally, this document is also meant for officials in governments, social security agencies and reimbursement agencies, since it provides the current state of thought in the area of RA management and is based on as much evidence as was available. In this regard, the economic valuation is also of significance; indeed, all recommendations are supported by cost-effectiveness data, with the exception of starting biological agents before synthetic DMARDs; indeed, this conclusion is further supported by a recent Cochrane meta-analyis which stated that in patients with early RA. biological agents plus MTX may not differ significantly from placebo plus MTX with risk ratios of 1.43 and $95 \%$ confidence intervals of 0.98 to $2.09 .{ }^{120}$ However, in this regard more research is needed, since the recommendation only pertains to limited exceptional patients whose treatment has not yet been studied economically. Indeed, several of the recommendations are more strongly based on expert opinion and on clinical practice that has emerged in certain institutions than on available evidence. It is here where the opportunity to garner evidence has to meet or disprove expert opinion or practice and this is in part, the driver for the research agenda. Also, as has been the case over the past decade, new data on existing or new drugs or therapeutic strategies will emerge over the next few years. Therefore, we will carefully watch developments in the field and assume that an amendment of these recommendations may be needed in 2 years. Finally, irrespective of availability or affordability of certain agents, these recommendations can also serve as a template for national societies which can adapt them to national clinical practices while remaining within their general framework.

Authors affiliations ${ }^{1}$ Division of Rheumatology, Department of Medicine 3, Medical University of Vienna, Vienna, Austria

${ }^{2} 2$ nd Department of Medicine, Hietzing Hospital, Vienna, Austria

${ }^{3}$ Department of Internal Medicine/Rheumatology, University Hospital Maastricht, Maastricht, The Netherlands

${ }^{4}$ Department of Rheumatology, Leiden University Medical Centre, Leiden, The Netherlands

${ }^{5}$ Rheumatology B Department, Paris Descartes University, Cochin Hospital, Paris, France

${ }^{6}$ Section of Musculoskeletal Disease, Leeds Institute of Molecular Medicine, University of Leeds, Leeds, UK

${ }^{7}$ Pierre et Marie Curie University-Paris VI, APHP, Rheumatology, Pitié-Salpétrière Hospital, Paris, France

${ }^{8}$ Department of Rheumatology and Clinical Immunology, University Medical Center Utrecht, Utrecht, The Netherlands 
${ }^{9}$ Department of Rheumatology and Clinical Immunology, Humboldt University, Charité Hospital, Berlin, Germany

${ }^{10}$ Service d'Immuno-Rhumatologie, Montpellier University, Lapeyronie Hospital, Montpellier, France

${ }^{11}$ Academic Clinical Unit of Rheumatology, Department of Internal Medicine, University of Genova, Genova, Italy

${ }^{12}$ Division of Rheumatology, University Hospitals, Geneva, Switzerland

${ }^{13}$ Santiago University Clinical Hospital, Santiago University School of Medicine, Santiago de Compostela, Spain

${ }^{14}$ EULAR Standing Committee of People with Arthritis/Rheumatism in Europe, Zurich, Switzerland

${ }^{15}$ Department of Rheumatology, Diakonhjemmet Hospital, Oslo, Norway

${ }^{16}$ La Paz Hospital, Madrid, Spain

${ }^{17}$ University of Glasgow, Glasgow, UK

${ }^{18}$ Institute of Rheumatology and Clinic of Rheumatology, Charles University, Prague, Czech Republic

${ }^{19}$ Department of Rheumatology, Radboud University Nijmegen Medical Centre, Nijmegen, The Netherlands

${ }^{20}$ King's College School of Medicine, Weston Education Centre, London, UK

${ }^{21}$ Department of Rheumatology, Jyväskylä Central Hospital, Jyväskylä, Finland

${ }^{22}$ Rheumatology Unit, Department of Clinical Medicine and Medical Therapy, Sapienza Università di Roma, Rome, Italy

${ }^{23}$ Rheumatology Unit, Department of Medicine, Karolinska Institutet, Karolinska University Hospital, Solna, Sweden

${ }^{24}$ Oregon Health and Science University, Portland, Oregon, USA

${ }^{25}$ Division of Clinical Decision Making, Informatics and Telemedicine, Tufts University School of Medicine, Boston, Massachusetts, USA

${ }^{26}$ German Rheumatism Research Centre and Charité University Medicine, Berlin, Germany

Funding EULAR.

Competing interests The following authors declare that they have no potential conflict of interest: CG-V, SG, RK, MK, JN, MS, JW. The following authors declare a potential conflict of interest having received grant support and/or honoraria for consultations and/or for presentations as indicated; JSS: Abbott, Amgen, BMS, Centocor, Pfizer, Roche, Schering-Plough,UCB, Sanofi-Aventis, Wyeth; RL: Abbott, Amgen, BMS, Centocor, Merck, Pfizer, Schering-Plough, UCB, Wyeth; FCB: Abbott, Schering-Plough, Wyeth; MD: Pfizer, Wyeth, Abbott, Roche, Novartis, Nordic Pharma, BMS, UCB; PE: Abbot, BMS, Centocor, Pfizer, Roche, Schering-Plough,UCB, Sanofi-Aventis, Wyeth; MS: Abbott; DA: Abbott, Roche, Schering-Plough, BMS, UCB, Sanofi-Aventis; MB: Roche, Abbott, BMS, Wyeth; LG: Abbott, Schering-Plough, Roche, UCB, BMS, Wyeth; TH: Schering Plough, BMS, Biotest, Wyeth, Novartis, Roche, Sanofi-Aventis, Abbott, Axis-Shield; JWJWB: Abbott, Roche, Wyeth, Schering Plough, Merck, Pfizer, UCB, BMS; GB: Abbott, Wyeth, Schering-Plough, Roche and UCB; BC: Abbott,BMS, Roche, Schering, UCB,Wyeth; MC: Sanofi-Aventis, BMS, Pfizer, Abbott; CG: Roche, BMS, Abbott, Essex, Wyeth, UCB; JG-R: Abbott, BMS, Pfizer, Roche, Schering-Plough,Wyeth and UCB; TKK: Abbott, BMS, Roche, Schering-Plough,Wyeth, Pfizer, MSD and UCB; EMM: Wyeth/Pfizer, Roche, Abbott Schering Plough/MSD; IM: Schering Plough, Pfizer, Roche and BMS; KP: Roche, Abbott, BMS, Pfizer, MSD; PvR: Abbott, BMS, Roche, Sanofi-Aventis, Schering-Plough, UCB, Wyeth; DLS: MSD, Pfizer, Novartis, Roche, Wyeth, Novartis, Schering Plough; TS: Abbott, Pfizer, Sanofi-Aventis, Roche, UCB; GV: Abbott, BMS, Roche, Sanofi-Aventis, Schering-Plugh, UCB, Wyeth; RvV: Abbott, Pfizer/ Wyeth, Roche, Schering-Plough, BMS, UCB; KLW: Amgen, Wyeth, UCB, Genentech; AZ: Abbott, Amgen, BMS, Essex/Schering-Plough, Merck, Pfizer, Roche, Sanofi, UCB, Wyeth; DvdH: Abbott, Amgen, BMS, Centocor, Chugai, Merck, Pfizer, Roche, ScheringPlough,UCB, Wyeth. Francis Berenbaum was the Handling Editor.

Provenance and peer review Not commissioned; externally peer reviewed.

\section{REFERENCES}

1. Smolen JS, Aletaha D, Koeller M, et al. New therapies for treatment of rheumatoid arthritis. Lancet 2007;370:1861-74.

2. Visser $\mathbf{K}$, van der Heijde D. Optimal dosage and route of administration of methotrexate in rheumatoid arthritis: a systematic review of the literature. Ann Rheum Dis 2009;68:1094-9

3. Svensson B, Boonen A, Albertsson K, et al. Low-dose prednisolone in addition to the initial disease-modifying antirheumatic drug in patients with early active rheumatoid arthritis reduces joint destruction and increases the remission rate: a two-year randomized trial. Arthritis Rheum 2005;52:3360-70.

4. Wassenberg S, Rau R, Steinfeld P, et al. Very low-dose prednisolone in early rheumatoid arthritis retards radiographic progression over two years: a multicenter, double-blind, placebo-controlled trial. Arthritis Rheum 2005;52:3371-80.

5. van Everdingen AA, Jacobs JW, Siewertsz van Reesema DR, et al. Low-dose prednisone therapy for patients with early active rheumatoid arthritis: clinical efficacy, disease-modifying properties, and side effects: a randomized, double-blind, placebocontrolled clinical trial. Ann Intern Med 2002;136:1-12.

6. Möttönen TT, Hannonen PJ, Boers M. Combination DMARD therapy including corticosteroids in early rheumatoid arthritis. Clin Exp Rheumatol 1999;17 (6 Suppl 18):S59-65
7. Boers $\mathbf{M}$, Verhoeven AC, Markusse HM, et al. Randomised comparison of combined step-down prednisolone, methotrexate and sulphasalazine with sulphasalazine alone in early rheumatoid arthritis. Lancet 1997;350:309-18.

8. van der Heide A, Jacobs JW, Bijlsma JW, et al. The effectiveness of early treatment with "second-line" antirheumatic drugs. A randomized, controlled trial. Ann Intern Med 1996;124:699-707.

9. Emery P, Breedveld FC, Dougados M, et al. Early referral recommendation for newly diagnosed rheumatoid arthritis: evidence based development of a clinical guide. Ann Rheum Dis 2002;61:290-7.

10. Nell VP, Machold KP, Eberl G, et al. Benefit of very early referral and very early therapy with disease-modifying anti-rheumatic drugs in patients with early rheumatoid arthritis. Rheumatology (Oxford) 2004;43:906-14.

11. Grigor C, Capell H, Stirling A, et al. Effect of a treatment strategy of tight control for rheumatoid arthritis (the TICORA study): a single-blind randomised controlled trial. Lancet 2004;364:263-9.

12. Goekoop-Ruiterman YP, de Vries-Bouwstra JK, Allaart CF, et al. Comparison of treatment strategies in early rheumatoid arthritis: a randomized trial. Ann Intern Med 2007; 146:406-15

13. Verstappen SM, Jacobs JW, van der Veen MJ, et al. Intensive treatment with methotrexate in early rheumatoid arthritis: aiming for remission. Computer Assisted Management in Early Rheumatoid Arthritis (CAMERA, an open-label strategy trial). Ann Rheum Dis 2007:66:1443-9.

14. Fransen J, Moens HB, Speyer I, et al. Effectiveness of systematic monitoring of rheumatoid arthritis disease activity in daily practice: a multicentre, cluster randomised controlled trial. Ann Rheum Dis 2005:64:1294-8.

15. Schoels M, Aletaha D, Smolen JS, et al. Follow-up standards and treatment targets in rheumatoid arthritis (RA): results of a questionnaire at the EULAR 2008. Ann Rheum Dis 2010;69:575-8.

16. Breedveld FC. For EULAR. The Eight EULAR 2012 Objectives. http://www.eular.org/ myUploadData/files/Stene\%20Prize\%202009\%20Booklet.pdf. 2009

17. Dougados M, Betteridge N, Burmester GR, et al. EULAR standardised operating procedures for the elaboration, evaluation, dissemination, and implementation of recommendations endorsed by the EULAR standing committees. Ann Rheum Dis 2004:63:1172-6.

18. Gaujoux-Viala C, Smolen JS, Landewé R, et al. Current evidence for the management of rheumatoid arthritis with synthetic disease-modifying antirheumatic drugs: systematic literature review informing the EULAR recommendations for the management of rheumatoid arthritis. Ann Rheum Dis 2010;69:1004-09.

19. Nam JL, Winthrop K, van Vollenhoven R, et al. Current evidence for the management of rheumatoid arthritis with biological disease-modifying antirheumatic drugs: a systematic literature review informing the EULAR recommendations for the management of RA. Ann Rheum Dis 2010;69:976-986.

20. Gorter SL, Bijlsma H, Cutolo M, et al. Current evidence for the management of rheumatoid arthritis with glucocorticoids: a systematic literature review informing the EULAR recommendations for the management of rheumatoid arthritis. Ann Rheum Dis 2010;69:1010-14.

21. Knevel R, Schoels M, Huizinga TWJ, et al. Current evidence for a strategic approach to the management of rheumatoid arthritis with disease-modifying antirheumatic drugs: a systematic literature review informing the EULAR recommendations for the management of rheumatoid arthritis. Ann Rheum Dis 2010;69:987-994.

22. Schoels $\mathbf{M}$, Wong J, Scott DL, et al. Economic aspects of treatment options in rheumatoid arthritis: a systematic literature review informing the EULAR recommendations for the management of rheumatoid arthritis. Ann Rheum Dis 2010;69:995-1003.

23. Oxford Center for Evidence Based Medicine. Levels of Evidence, 2009.

24. Ward MM, Leigh JP, Fries JF. Progression of functional disability in patients with rheumatoid arthritis. Associations with rheumatology subspecialty care. Arch Intern Med 1993;153:2229-37.

25. Criswell LA, Such CL, Yelin EH. Differences in the use of second-line agents and prednisone for treatment of rheumatoid arthritis by rheumatologists and nonrheumatologists. J Rheumatol 1997;24:2283-90

26. Rat AC, Henegariu V, Boissier MC. Do primary care physicians have a place in the management of rheumatoid arthritis? Joint Bone Spine 2004;71:190-7.

27. Lacaille D, Anis AH, Guh DP, et al. Gaps in care for rheumatoid arthritis: a population study. Arthritis Rheum 2005;53:241-8.

28. Solomon DH, Bates DW, Panush RS, et al. Costs, outcomes, and patient satisfaction by provider type for patients with rheumatic and musculoskeletal conditions: a critical review of the literature and proposed methodologic standards. Ann Intern Med 1997; 127:52-60.

29. National Collaborating Centre for Chronic Conditions. Rheumatoid Arthritis: National Clinical Guideline for Management and Treatment in Adults. London: Royal College of Physicians, February 2009.

30. Michaud K, Messer J, Choi HK, et al. Direct medical costs and their predictors in patients with rheumatoid arthritis: a three-year study of 7,527 patients. Arthritis Rheum 2003:48:2750-62.

31. Rat AC, Boissier MC. Rheumatoid arthritis: direct and indirect costs. Joint Bone Spine 2004:71:518-24.

32. Pugner KM, Scott DI, Holmes JW, et al. The costs of rheumatoid arthritis: an international long-term view. Semin Arthritis Rheum 2000;29:305-20. 
33. Yelin $\mathbf{E}$, Wanke LA. An assessment of the annual and long-term direct costs of rheumatoid arthritis: the impact of poor function and functional decline. Arthritis Rheum 1999:42:1209-18.

34. Kobelt G, Jönsson B. The burden of rheumatoid arthritis and access to treatment: outcome and cost-utility of treatments. Eur J Health Econ 2008;8(Suppl 2):S95-106.

35. Spalding JR, Hay J. Cost effectiveness of tumour necrosis factor-alpha inhibitors as first-line agents in rheumatoid arthritis. Pharmacoeconomics 2006:24:1221-32.

36. Emery P, Breedveld FC, Hall S, et al. Comparison of methotrexate monotherapy with a combination of methotrexate and etanercept in active, early, moderate to severe rheumatoid arthritis (COMET): a randomised, double-blind, parallel treatment trial. Lancet 2008;372:375-82.

37. Nandi P, Kingsley GH, Scott DL. Disease-modifying antirheumatic drugs other than methotrexate in rheumatoid arthritis and seronegative arthritis. Curr Opin Rheumatol 2008:20:251-6

38. Plosker GL, Croom KF. Sulfasalazine: a review of its use in the management of rheumatoid arthritis. Drugs 2005:65:1825-49.

39. Dougados M, Emery P, Lemmel EM, et al. Efficacy and safety of leflunomide and predisposing factors for treatment response in patients with active rheumatoid arthritis: RELIEF 6-month data. J Rheumato/ 2003;30:2572-9.

40. Lard LR, Visser H, Speyer I, et al. Early versus delayed treatment in patients with recent-onset rheumatoid arthritis: comparison of two cohorts who received different treatment strategies. Am J Med 2001;111:446-51.

41. Aletaha D, Neogi T, Silman A, et al. The American College of Rheumatology / European League Against Rheumatism Classification and Diagnostic Criteria fo Rheumatoid Arthritis. Ann Rheum Dis 2010. (Submitted).et al, unpublished data)" and renumber the subsequent references.]

42. Möttönen T, Hannonen P, Leirisalo-Repo $\mathrm{M}$, et al. Comparison of combination therapy with single-drug therapy in early rheumatoid arthritis: a randomised trial. FIN-RACo trial group. Lancet 1999;353:1568-73.

43. Smolen JS, Han C, van der Heijde DM, et al. Radiographic changes in rheumatoid arthritis patients attaining different disease activity states with methotrexate monotherapy and infliximab plus methotrexate: the impacts of remission and tumour necrosis factor blockade. Ann Rheum Dis 2009;68:823-7.

44. Molenaar ET, Voskuyl AE, Dijkmans BA. Functional disability in relation to radiological damage and disease activity in patients with rheumatoid arthritis in remission. $J$ Rheumatol 2002:29:267-70.

45. Molenaar ET, Voskuyl AE, Dinant HJ, et al. Progression of radiologic damage in patients with rheumatoid arthritis in clinical remission. Arthritis Rheum 2004;50:36-42.

46. Aletaha D, Funovits J, Smolen JS. The importance of reporting disease activity states in rheumatoid arthritis clinical trials. Arthritis Rheum 2008:58:2622-31.

47. Aletaha D, Funovits J, Breedveld FC, et al. Rheumatoid arthritis joint progression in sustained remission is determined by disease activity levels preceding the period of radiographic assessment. Arthritis Rheum 2009; 60:1242-9

48. Smolen JS, Aletaha D, Bijlsma JWJ, et al. Treating rheumatoid arthritis to target: recommendations of an international task force. Ann Rheum Dis 2010; 69:631-7.

49. Goekoop-Ruiterman YP, de Vries-Bouwstra JK, Allaart CF, et al. Clinical and radiographic outcomes of four different treatment strategies in patients with early rheumatoid arthritis (the BeSt study): a randomized, controlled trial. Arthritis Rheum 2005:52:3381-90.

50. Aletaha D, Funovits J, Keystone EC, et al. Disease activity early in the course of treatment predicts response to therapy after one year in rheumatoid arthritis patients. Arthritis Rheum 2007;56:3226-35

51. Aletaha D, Smolen JS. The definition and measurement of disease modification in inflammatory rheumatic diseases. Rheum Dis Clin North Am 2006;32:9-44, vii.

52. Weinblatt ME. Efficacy of methotrexate in rheumatoid arthritis. Br J Rheumatol 1995;34(Suppl 2):43-8.

53. Aletaha D, Smolen JS. Effectiveness profiles and dose dependent retention of traditional disease modifying antirheumatic drugs for rheumatoid arthritis. An observational study. J Rheumato/ 2002;29:1631-8.

54. Pincus T, Yazici Y, Sokka T, et al. Methotrexate as the "anchor drug" for the treatment of early rheumatoid arthritis. Clin Exp Rheumatol 2003;21(Suppl 31):S178-85.

55. Klareskog $\mathbf{L}$, van der Heijde D, de Jager JP, et al. Therapeutic effect of the combination of etanercept and methotrexate compared with each treatment alone in patients with rheumatoid arthritis: double-blind randomised controlled trial. Lancet 2004;363:675-81.

56. Breedveld FC, Weisman MH, Kavanaugh AF, et al. The PREMIER study: a multicenter, randomized, double-blind clinical trial of combination therapy with adalimumab plus methotrexate versus methotrexate alone or adalimumab alone in patients with early, aggressive rheumatoid arthritis who had not had previous methotrexate treatment. Arthritis Rheum 2006;54:26-37.

57. Maini RN, Breedveld FC, Kalden JR, et al. Therapeutic efficacy of multiple intravenous infusions of anti-tumor necrosis factor alpha monoclonal antibody combined with low-dose weekly methotrexate in rheumatoid arthritis. Arthritis Rheum 1998;41:1552-63.

58. Edwards JC, Szczepanski L, Szechinski J, et al. Efficacy of B-cell-targeted therapy with rituximab in patients with rheumatoid arthritis. N Engl J Med 2004;350:2572-81.
59. Maini RN, Taylor PC, Szechinski J, et al. Double-blind randomized controlled clinica trial of the interleukin-6 receptor antagonist, tocilizumab, in European patients with rheumatoid arthritis who had an incomplete response to methotrexate. Arthritis Rheum 2006; 54:2817-29.

60. Salliot C, van der Heijde D. Long-term safety of methotrexate monotherapy in patients with rheumatoid arthritis: a systematic literature research. Ann Rheum Dis 2009;68:1100-4.

61. St Clair EW, van der Heijde DM, Smolen JS, et al. Combination of infliximab and methotrexate therapy for early rheumatoid arthritis: a randomized, controlled trial. Arthritis Rheum 2004:50:3432-43.

62. Donahue KE, Gartlehner G, Jonas DE, et al. Systematic review: comparative effectiveness and harms of disease-modifying medications for rheumatoid arthritis. Ann Intern Med 2008;148:124-34.

63. Rau R, Herborn G, Menninger H, et al. Radiographic outcome after three years of patients with early erosive rheumatoid arthritis treated with intramuscular methotrexate or parenteral gold. Extension of a one-year double-blind study in 174 patients. Rheumatology (Oxford) 2002; 41:196-204

64. Weinblatt ME, Reda D, Henderson W, et al. Sulfasalazine treatment for rheumatoid arthritis: a metaanalysis of 15 randomized trials. J Rheumatol 1999:26:2123-30.

65. Hamilton J, Mclnnes IB, Thomson EA, et al. Comparative study of intramuscular gold and methotrexate in a rheumatoid arthritis population from a socially deprived area. Ann Rheum Dis 2001;60:566-72.

66. Lehman AJ, Esdaile JM, Klinkhoff AV, et al. A 48-week, randomized, double-blind, double-observer, placebo-controlled multicenter trial of combination methotrexate and intramuscular gold therapy in rheumatoid arthritis: results of the METGO study. Arthritis Rheum 2005;52:1360-70.

67. Suarez-Almazor ME, Belseck E, Shea B, et al. Antimalarials for treating rheumatoid arthritis. Cochrane Database Syst Rev 2000;4:CD000959.

68. O'Dell JR, Haire CE, Erikson N, et al. Treatment of rheumatoid arthritis with methotrexate alone, sulfasalazine and hydroxychloroquine, or a combination of all three medications. N Engl J Med 1996;334:1287-91.

69. Calgüneri M, Pay S, Caliskaner Z, et al. Combination therapy versus monotherapy for the treatment of patients with rheumatoid arthritis. Clin Exp Rheumatol 1999:17:699-704

70. van der Heijde DM, van Riel PL, Nuver-Zwart IH, et al. Sulphasalazine versus hydroxychloroquine in rheumatoid arthritis: 3-year follow-up. Lancet 1990;335:539.

71. McCarty DJ. Suppress rheumatoid inflammation early and leave the pyramid to the Egyptians. J Rheumatol 1990;17:1115-18.

72. Tugwell P, Pincus T, Yocum D, et al.; The Methotrexate-Cyclosporine Combination Study Group. Combination therapy with cyclosporine and methotrexate in severe rheumatoid arthritis. N Engl J Med 1995;333:137-41.

73. Kremer JM, Genovese MC, Cannon GW, et al. Concomitant leflunomide therapy in patients with active rheumatoid arthritis despite stable doses of methotrexate. A randomized, double-blind, placebo-controlled trial. Ann Intern Med 2002;137:726-33.

74. Smolen JS, Aletaha D, Keystone E. Superior efficacy of combination therapy for rheumatoid arthritis: fact or fiction? Arthritis Rheum 2005;52:2975-83.

75. Dougados $\mathbf{M}$, Combe B, Cantagrel A, et al. Combination therapy in early rheumatoid arthritis: a randomised, controlled, double blind 52 week clinical trial of sulphasalazine and methotrexate compared with the single components. Ann Rheum Dis 1999:58:220-5.

76. Haagsma CJ, van Riel PL, de Jong AJ, et al. Combination of sulphasalazine and methotrexate versus the single components in early rheumatoid arthritis: a randomized, controlled, double-blind, 52 week clinical trial. Br J Rheumatol 1997;36:1082-8.

77. Schipper LG, Fransen J, Barrera P, et al. Methotrexate therapy in rheumatoid arthritis after failure to sulphasalazine: to switch or to add? Rheumatology (Oxford) 2009;48:1247-53.

78. Katchamart W, Trudeau J, Phumethum V, et al. Efficacy and toxicity of methotrexate (MTX) monotherapy versus MTX combination therapy with non-biological diseasemodifying antirheumatic drugs in rheumatoid arthritis: a systematic review and metaanalysis. Ann Rheum Dis 2009:68:1105-12.

79. Kirwan JR. The effect of glucocorticoids on joint destruction in rheumatoid arthritis. The Arthritis and Rheumatism Council Low-Dose Glucocorticoid Study Group. N Engl J Med 1995;333:142-6

80. Kirwan JR, Bijlsma JW, Boers M, et al. Effects of glucocorticoids on radiological progression in rheumatoid arthritis. Cochrane Database Syst Rev 2007;1:CD006356.

81. Hoes JN Jacobs JW Verstappen SM, et al. Adverse events of low- to mediumdose oral glucocorticoids in inflammatory diseases: a meta-analysis. Ann Rheum Dis 2009;68:1833-8.

82. Hoes JN Jacobs JW Boers $M$, et al. EULAR evidence-based recommendations on the management of systemic glucocorticoid therapy in rheumatic diseases. Ann Rheum Dis 2007:66:1560-7.

83. Scott DL, Symmons DP, Coulton BL, et al. Long-term outcome of treating rheumatoid arthritis: results after 20 years. Lancet 1987;1:1108-11.

84. Rantapää-Dahlqvist S. Diagnostic and prognostic significance of autoantibodies in early rheumatoid arthritis. Scand J Rheumato/ 2005:34:83-96.

85. Nell VP, Machold KP, Stamm TA, et al. Autoantibody profiling as early diagnostic and prognostic tool for rheumatoid arthritis. Ann Rheum Dis 2005:64:1731-6. 
86. van der Heijde DM, van Riel PL, van Leeuwen MA, et al. Prognostic factors for radiographic damage and physical disability in early rheumatoid arthritis. A prospective follow-up study of 147 patients. Br J Rheumatol 1992;31:519-25.

87. Smolen JS, Van Der Heijde DM, St Clair EW, et al. Predictors of joint damage in patients with early rheumatoid arthritis treated with high-dose methotrexate with or without concomitant infliximab: results from the ASPIRE trial. Arthritis Rheum 2006;54:702-10.

88. Vastesaeger $\mathbf{N}, \mathrm{Xu}$ S, Aletaha D, et al. A pilot risk model for the prediction of rapid radiographic progression in rheumatoid arthritis. Rheumatology (Oxford) 2009;:48:1114-21

89. van Vollenhoven RF, Ernestam S, Geborek P, et al. Addition of infliximab compared with addition of sulfasalazine and hydroxychloroquine to methotrexate in patients with early rheumatoid arthritis (Swefot trial): 1-year results of a randomised trial. Lancet 2009;374:459-66

90. Westhovens $\mathbf{R}$, Robles $M$, Ximenes $A C$, et al. Clinical efficacy and safety of abatacept in methotrexate-naive patients with early rheumatoid arthritis and poor prognostic factors. Ann Rheum Dis 2009;68:1870-7.

91. Rigby WF, Ferreccioli G, Greenwald $M$, et al. Rituximab improved physical function and quality of life in patients with early rheumatoid arthritis: results from a randomized active comparator placebo-controlled trial of rituximab in combination with methotrexate compared to methotrexate alone in pat. Ann Rheum Dis 2009;68(Suppl 3):581.

92. Bathon JM, Martin RW, Fleischmann RM, et al. A comparison of etanercept and methotrexate in patients with early rheumatoid arthritis. N Engl J Med 2000;343:1586-93.

93. Jones G, Sebba A, Gu J, et al. Comparison of tocilizumab monotherapy versus methotrexate monotherapy in patients with moderate to severe rheumatoid arthritis: the AMBITION study. Ann Rheum Dis 2010;69:88-96.

94. Nishimoto N, Hashimoto J, Miyasaka N, et al. Study of active controlled monotherapy used for rheumatoid arthritis, an IL-6 inhibitor (SAMURAI): evidence of clinical and radiographic benefit from an $\mathrm{x}$ ray reader-blinded randomised controlled trial of tocilizumab. Ann Rheum Dis 2007;66:1162-7.

95. Cohen S, Hurd E, Cush J, et al. Treatment of rheumatoid arthritis with anakinra, a recombinant human interleukin-1 receptor antagonist, in combination with methotrexate: results of a twenty-four-week, multicenter, randomized, double-blind, placebo-controlled trial. Arthritis Rheum 2002;46:614-24.

96. Gartlehner G, Hansen RA, Jonas BL, et al. The comparative efficacy and safety of biologics for the treatment of rheumatoid arthritis: a systematic review and metaanalysis. J Rheumatol 2006;33:2398-408.

97. Genovese MC, Becker JC, Schiff M, et al. Abatacept for rheumatoid arthritis refractory to tumor necrosis factor alpha inhibition. N Engl J Med 2005;353:1114-23.

98. Smolen JS, Kay J, Doyle MK, et al. Golimumab in patients with active rheumatoid arthritis after treatment with tumour necrosis factor alpha inhibitors (GO-AFTER study): a multicentre, randomised, double-blind, placebo-controlled, phase III trial. Lancet 2009;374:210-21.

99. Cohen SB, Emery P, Greenwald MW, et al. Rituximab for rheumatoid arthritis refractory to anti-tumor necrosis factor therapy: results of a multicenter, randomized, double-blind, placebo-controlled, phase III trial evaluating primary efficacy and safety at twenty-four weeks. Arthritis Rheum 2006;54:2793-806.

100. Emery $\mathbf{P}$, Keystone E, Tony HP, et al. IL-6 receptor inhibition with tocilizumab improves treatment outcomes in patients with rheumatoid arthritis refractory to anti-tumour necrosis factor biologicals: results from a 24-week multicentre randomised placebocontrolled trial. Ann Rheum Dis 2008;67:1516-23.

101. Gomez-Reino JJ, Carmona L. Switching TNF antagonists in patients with chronic arthritis: an observational study of 488 patients over a four-year period. Arthritis Res Ther 2006;8:R29.

102. Hyrich KL, Lunt M, Watson KD, et al. Outcomes after switching from one anti-tumor necrosis factor alpha agent to a second anti-tumor necrosis factor alpha agent in patients with rheumatoid arthritis: results from a large UK national cohort study. Arthritis Rheum 2007;56:13-20.
103. Finckh A, Ciurea A, Brulhart L, et al. Which subgroup of patients with rheumatoid arthritis benefits from switching to rituximab versus alternative anti-tumour necrosis factor (TNF) agents after previous failure of an anti-TNF agent? Ann Rheum Dis 2010;69:387-93

104. Smolen JS, Weinblatt ME. When patients with rheumatoid arthritis fail tumour necrosis factor inhibitors: what is the next step? Ann Rheum Dis 2008;67:1497-8.

105. Teng YK, Verburg RJ, Verpoort KN, et al. Differential responsiveness to immunoablative therapy in refractory rheumatoid arthritis is associated with level and avidity of anti-cyclic citrullinated protein autoantibodies: a case study. Arthritis Res Ther 2007;9:R106.

106. Moreland LW, Sewell KL, Trentham DE, et al. Interleukin-2 diphtheria fusion protein (DAB486IL-2) in refractory rheumatoid arthritis. A double-blind, placebo-controlled trial with open-label extension. Arthritis Rheum 1995;38:1177-86.

107. Smolen JS, Sokka T, Pincus T, et al. A proposed treatment algorithm for rheumatoid arthritis: aggressive therapy, methotrexate, and quantitative measures. Clin Exp Rheumato/ 2003;21(5 Suppl 31):S209-10.

108. ten Wolde S, Breedveld FC, Hermans J, et al. Randomised placebocontrolled study of stopping second-line drugs in rheumatoid arthritis. Lancet 1996;347:347-52.

109. ten Wolde S, Hermans J, Breedveld FC, et al. Effect of resumption of second line drugs in patients with rheumatoid arthritis that flared up after treatment discontinuation. Ann Rheum Dis 1997:56:235-9.

110. O'Mahony R, Richards A, Deighton C, et al. Withdrawal of DMARDs in patients with rheumatoid arthritis: a systematic review and meta-analysis. Ann Rheum Dis Published Online First: 17 February 2009 doi:10.1136/ard.2008.105577.

111. Lipsky PE, van der Heijde DM, St Clair EW, et al. Infliximab and methotrexate in the treatment of rheumatoid arthritis. Anti-Tumor Necrosis Factor Trial in Rheumatoid Arthritis with Concomitant Therapy Study Group. N Engl J Med 2000:343:1594-602

112. Keystone EC, Kavanaugh AF, Sharp JT, et al. Radiographic, clinical, and functional outcomes of treatment with adalimumab la human anti-tumor necrosis factor monoclonal antibody) in patients with active rheumatoid arthritis receiving concomitant methotrexate therapy: a randomized, placebo-controlled, 52-week trial. Arthritis Rheum 2004;50:1400-11.

113. Weinblatt ME, Kremer JM, Bankhurst AD, et al. A trial of etanercept, a recombinant tumor necrosis factor receptor:Fc fusion protein, in patients with rheumatoid arthritis receiving methotrexate. N Engl J Med 1999;340:253-9.

114. Soubrier M, Puéchal X, Sibilia J, et al. Evaluation of two strategies (initial methotrexate monotherapy vs its combination with adalimumab) in management of early active rheumatoid arthritis: data from the GUEPARD trial. Rheumatology (Oxford) 2009;48:1429-34

115. Combe B, Landewe R, Lukas C, et al. EULAR Recommendations for the Management of Early Arthritis: Report of a Task Force of the European Standing Committee for International Clinical Studies Including Therapeutics (ESCISIT). Ann Rheum Dis 2007;66:34-45

116. Aletaha D, Landewe R, Karonitsch T, et al. Reporting disease activity in clinical trials of patients with rheumatoid arthritis: EULAR/ACR collaborative recommendations. Ann Rheum Dis 2008;67:1360-4.

117. Aletaha D, Landewe R, Karonitsch T, et al. Reporting disease activity in clinical trials of patients with rheumatoid arthritis: EULAR/ACR collaborative recommendations. Arthritis Rheum 2008:59:1371-7.

118. American College of Rheumatology Subcommittee on Rheumatoid Arthritis Guidelines. Guidelines for the management of rheumatoid arthritis: 2002 update. Arthritis Rheum 2002;46:328-46

119. Saag KG, Teng GG, Patkar NM, et al. American College of Rheumatology 2008 recommendations for the use of nonbiologic and biologic disease-modifying antirheumatic drugs in rheumatoid arthritis. Arthritis Rheum 2008;59:762-84.

120. Singh JA, Christensen R, Wells GA, et al. Biologics for rheumatoid arthritis: an overview of Cochrane reviews. Cochrane Database Syst Rev 2009; (4): CD007848. 


\section{Corrections}

The department of one of the authors who co-authored all of the below papers has found that the affiliations were not correct. The correct affiliations for Professor P Emery, for all of the below articles, are: ${ }^{1}$ Section of Musculoskeletal Disease, Leeds Institute of Molecular Medicine, University of Leeds; ${ }^{2}$ NIHR Leeds Musculoskeletal Biomedical Research Unit, Leeds Teaching Hospitals Trust, Leeds, UK.

1. Keystone E, Emery P, Peterfy CG, et al. Rituximab inhibits structural joint damage in patients with rheumatoid arthritis with an inadequate response to tumour necrosis factor inhibitor therapies. Ann Rheum Dis 2009;68:216-21.

2. Doward LC, McKenna SP, Whalley D, et al. The development of the L-OoL: a quality-of-life instrument specific to systemic lupus erythematosus. Ann Rheum Dis 2009;68:196-200.

3. Potter C, Hyrich KL, Tracey A, et al. Association of rheumatoid factor and anticyclic citrullinated peptide positivity, but not carriage of shared epitope or PTPN22 susceptibility variants, with anti-TNF response in RA. Ann Rheum Dis 2009;68:69-74.

4. Smolen JS, Han C, van der Heijde DM, et al.; Active-Controlled Study of Patients Receiving Infliximab for the Treatment of Rheumatoid Arthritis of Early Onset (ASPIRE) Study Group. Radiographic changes in rheumatoid arthritis patients attaining different disease activity states with methotrexate monotherapy and infliximab plus methotrexate: the impacts of remission and tumour necrosis factor blockade. Ann Rheum Dis 2009;68:823-7.

5. Buch MH, Boyle DL, Rosengren S, et al. Mode of action of abatacept in rheumatoid arthritis patients having failed tumour necrosis factor blockade: a histological, gene expression and dynamic magnetic resonance imaging pilot study. Ann Rheum Dis 2009;68:1220-7.

6. Emery P, Van Vollenhoven R, Ostergaard M, et al. Guidelines for initiation of antitumour necrosis factor therapy in rheumatoid arthritis: similarities and differences across Europe. Ann Rheum Dis 2009;68:456-9.

7. Bejarano V, Conaghan PG, Proudman SM, et al. Long-term efficacy and toxicity of ciclosporin A in combination with methotrexate in poor prognosis rheumatoid arthritis Ann Rheum Dis 2009;68:761-3.

8. Rudwaleit M, Landewé R, van der Heijde D, et al. The development of Assessment of SpondyloArthritis international Society classification criteria for axial spondyloarthritis (part I): classification of paper patients by expert opinion including uncertainty appraisal. Ann Rheum Dis 2009;68:770-6.

9. Bennett AN, Marzo-Ortega H, Emery P, et al.; Leeds Spondyloarthropathy Group. Diagnosing axial spondyloarthropathy. The new Assessment in SpondyloArthritis international Society criteria: MRI entering centre stage. Ann Rheum Dis 2009;68:765-7.

10. Marzo-Ortega H, McGonagle D, O'Connor P, et al. Baseline and 1-year magnetic resonance imaging of the sacroiliac joint and lumbar spine in very early inflammatory back pain. Relationship between symptoms, HLA-B27 and disease extent and persistence. Ann Rheum Dis 2009;68:1721-7.

11. Gilworth G, Emery P, Gossec L, et al. Adaptation and cross-cultural validation of the rheumatoid arthritis work instability scale (RA-WIS). Ann Rheum Dis 2009;68:1686-90.

12. Gilworth G, Emery P, Gossec L, et al. Adaptation and cross-cultural validation of the RA-WIS (Work Instability Scale). Ann Rheum Dis 2009;68:1686-90.

13. Jarrett SJ, Sivera F, Cawkwell LS, et al. MRI and clinical findings in patients with ankylosing spondylitis eligible for anti-tumour necrosis factor therapy after a short course of etoricoxib. Ann Rheum Dis 2009;68:1466-9.

14. Haugeberg G, Conaghan PG, Quinn $\mathrm{M}$, et al. Bone loss in patients with active early rheumatoid arthritis: infliximab and methotrexate compared with methotrexate treatment alone. Explorative analysis from a 12-month randomised, double-blind, placebo-controlled study. Ann Rheum Dis 2009;68:1898-901.

15. Genovese MC, Breedveld FC, Emery P, et al. Safety of biological therapies following rituximab treatment in rheumatoid arthritis patients. Ann Rheum Dis 2009;68:1894-7

16. Kekow J, Moots RJ, Emery P, et al. Patient-reported outcomes improve with etanercept plus methotrexate in active early rheumatoid arthritis and the improvement is strongly associated with remission: the COMET trial. Ann Rheum Dis 2010;69:222-5

17. Furst DE, Keystone EC, Fleischmann R, et al. Updated consensus statement on biological agents for the treatment of rheumatic diseases, 2009. Ann Rheum Dis 2010;69(Suppl 1):i2-29.

18. Freeston JE, Wakefield RJ, Conaghan PG, et al. A diagnostic algorithm for persistence of very early inflammatory arthritis: the utility of power Doppler ultrasound when added to conventional assessment tools. Ann Rheum Dis 2010;69:417-9.

19. Jones $\mathbf{E}$, Churchman SM, English A, et al. Mesenchymal stem cells in rheumatoid synovium: enumeration and functional assessment in relation to synovial inflammation level. Ann Rheum Dis 2010;69:450-7.

20. Alten RE, Zerbini C, Jeka S, et al. Efficacy and safety of pamapimod in patients with active rheumatoid arthritis receiving stable methotrexate therapy. Ann Rheum Dis 2010;69:364-7.
21. Machold KP, Landewé R, Smolen JS, et al. The Stop Arthritis Very Early (SAVE) trial, an international multicentre, randomised, double-blind, placebo-controlled trial on glucocorticoids in very early arthritis. Ann Rheum Dis 2010;69:495-502.

22. Schoels M, Knevel R, Aletaha D, et al. Evidence for treating rheumatoid arthritis to target: results of a systematic literature search. Ann Rheum Dis 2010;69:638-43.

23. Smolen JS, Aletaha D, Bijlsma JW, et al.; T2T Expert Committee. Treating rheumatoid arthritis to target: recommendations of an international task force. Ann Rheum Dis 2010;69:631-7.

24. Burr ML, Naseem H, Hinks A, et al.; BIRAC Consortium; YEAR Consortium. PADI4 genotype is not associated with rheumatoid arthritis in a large UK Caucasian population. Ann Rheum Dis 2010;69:666-70.

25. Emery $\mathbf{P}$, Durez P, Dougados $\mathrm{M}$, et al. Impact of T-cell costimulation modulation in patients with undifferentiated inflammatory arthritis or very early rheumatoid arthritis: a clinical and imaging study of abatacept (the ADJUST trial). Ann Rheum Dis 2010;69:510-16.

26. Bennett AN, Rehman A, Hensor EM, et al. The fatty Romanus lesion: a noninflammatory spinal MRI lesion specific for axial spondyloarthropathy. Ann Rheum Dis 2010;69:891-4.

27. Nam JL, Winthrop KL, van Vollenhoven RF, et al. Current evidence for the management of rheumatoid arthritis with biological disease-modifying antirheumatic drugs: a systematic literature review informing the EULAR recommendations for the management of RA. Ann Rheum Dis 2010;69:976-86.

28. Smolen JS, Landewé R, Breedveld FC, et al. EULAR recommendations for the management of rheumatoid arthritis with synthetic and biological disease-modifying antirheumatic drugs. Ann Rheum Dis 2010;69:964-75.

29. Tan RJ, Gibbons LJ, Potter C, et al.; BRAGGSS. Investigation of rheumatoid arthritis susceptibility genes identifies association of AFF3 and CD226 variants with response to anti-tumour necrosis factor treatment. Ann Rheum Dis 2010;69:1029-35.

30. Robinson JI, Barrett JH, Taylor JC, et al.; YEAR Consortium; BRAGGSS. Dissection of the FCGR3A association with RA: increased association in men and with autoantibody positive disease. Ann Rheum Dis 2010;69:1054-7.

31. Cohen SB, Keystone E, Genovese MC, et al. Continued inhibition of structural damage over 2 years in patients with rheumatoid arthritis treated with rituximab in combination with methotrexate. Ann Rheum Dis 2010;69:1158-61.

32. Haugeberg G, Bennett AN, McGonagle D, et al. Bone loss in very early inflammatory back pain in undifferentiated spondyloarthropathy: a 1-year observational study. Ann Rheum Dis 2010;69:1364-6.

33. Schoels M, Aletaha D, Smolen JS, et al. Follow-up standards and treatment targets in rheumatoid arthritis: results of a questionnaire at the EULAR 2008. Ann Rheum Dis 2010;69:575-8

34. Eyre S, Flynn E, Martin P, et al. No evidence for association of the KLF12 gene with rheumatoid arthritis in a large UK cohort. Ann Rheum Dis 2010;69:1407-8.

35. Eyre S, Hinks A, Flynn E, et al. Confirmation of association of the REL locus with rheumatoid arthritis susceptibility in the UK population. Ann Rheum Dis 2010;69:1572-3

36. Orozco G, Eyre S, Hinks A, et al.; Wellcome Trust Case Control consortium YEAR Consortium. Association of CD40 with rheumatoid arthritis confirmed in a large UK case-control study. Ann Rheum Dis 2010;69:813-16.

37. Emery $\mathbf{P}$, Durez P, Dougados $M$, et al. Impact of T-cell costimulation modulation in patients with undifferentiated inflammatory arthritis or very early rheumatoid arthritis: a clinical and imaging study of abatacept (the ADJUST trial). Ann Rheum Dis 2010;69:510-16

38. Saleem B, Keen $\mathrm{H}$, Goeb V, et al. Patients with RA in remission on TNF blockers: when and in whom can TNF blocker therapy be stopped? Ann Rheum Dis 2010;69:1636-42.

39. Barkham N, Coates LC, Keen H, et al. Double-blind placebo-controlled trial of etanercept in the prevention of work disability in ankylosing spondylitis. Ann Rheum Dis 2010;69:1926-8.

40. Emery P, Deodhar A, Rigby WF, et al. Efficacy and safety of different doses and retreatment of rituximab: a randomised, placebo-controlled trial in patients who are biological naive with active rheumatoid arthritis and an inadequate response to methotrexate (Study Evaluating Rituximab's Efficacy in MTX iNadequate rEsponders (SERENE)). Ann Rheum Dis 2010;69:1629-35.

41. Dixon WG, Hyrich KL, Watson KD, et al.; BSRBR Control Centre Consortium; British Society for Rheumatology Biologics Register. Influence of anti-TNF therapy on mortality in patients with rheumatoid arthritis-associated interstitial lung disease: results from the British Society for Rheumatology Biologics Register. Ann Rheum Dis 2010;69:1086-91. 